Agric. Admin. \& Extension 28 (1988) 227-238

\title{
National Agricultural Research Programmes in Sahelian Countries of West Africa: Problems and Recommendations*
}

\author{
Kanayo F. Nwanze \\ International Crops Research Institute for the Semi-Arid Tropics (ICRISAT), \\ Patancheru PO Andhra Pradesh 502 324, India
}

(Received 11 June 1987; accepted 19 August 1987)

\begin{abstract}
$S U M M A R Y$
Increasing food production in Africa through augmentation of the area of cultivated land is becoming less feasible thus emphasizing the need for increasing the productivity of the existing area to meet the objectives of national food security programmes. Several factors, however, negate the achievement of this goal. This paper focuses on the eight countries of the West African Sahel and discusses the implication of the lack of a critical mass of indigenous scientists in national programmes for conducting adaptive research on existing technologies or generating new ones for the particular situations of the region. The problems associated with these programmes are presented in the light of the number and calibre of personnel in agricultural research, the place of agriculture in national development, and the impact of foreign technical assistance. Measures for improving the domestic capacity of national programmes especially as they relate to training, are discussed. Regionalisation and networking programmes are also suggested as possible alternatives.
\end{abstract}

\section{BACKGROUND}

One of the components of any national strategy to ensure food security is to increase food production. Records show that in Africa for the period

* Submitted as JA No. 694 by the International Crops Research Institute for the Semi-Arid Tropics (ICRISAT).

Agric. Admin. \& Extension 0269-7475/88/\$03.50 (C) Elsevier Applied Science Publishers Ltd, England, 1988. Printed in Great Britain 
1960-79, there was a modest increase in total food production. ${ }^{18}$ The lowincome semi-arid countries of West Africa, otherwise referred to as the Sahel, registered $1 \cdot 1$ per cent average annual growth rate of total volume of production for the period, 1969-79. However, the average annual growth of total production per capita for the same period was -1.2 per cent, indicating an actual decline in productivity. Thus, the increased volume in production was a result of an increase in area cultivated.

Eicher claims that 25 years after independence, Africa is importing food, while vast tracts of land lie idle and foreign assistance is at record levels. ${ }^{4}$ Past models of African agricultural development have also tended to assume a generalized land surplus situation. ${ }^{6,9}$ But there is substantial evidence that the land base and changing land use patterns lead to quite different conclusions. ${ }^{8.11 .13}$ A number of factors contribute to this body of evidence, such as: non-suitability for agriculture due to increasing desertification; presence of ferrogenous hard pans; frequent flooding; a high degree of micro-variability in land quality; and the rapid decline of soil fertility under continuous cultivation. Combined with these factors is a rapid population growth rate that contributes to the pressure on the land so that by the end of this century in most of Africa there will be few regions where agricultural production can be increased by expanding the area under cultivation. The implication of this statement is that increased agricultural production must be generated by increased land productivity. Increased land productivity in turn implies either the use of existing technologies, directly or through adaptation, or the generation of new technologies to bring about not only increased productivity but also for the maintenance of that productivity.

The scientific ability of African nations to generate this change through the use of existing technologies or the generation of new ones is highly questionable-and justifiably so. Spencer argues that even if internal policies had been correct or external economic factors favourable, the situation would not have been so bad, since research has not produced a large enough stock of technologies to assure a big increase in aggregate agricultural output, particularly food supply. ${ }^{16}$ But the issue is: why does this lack exist, and why is there a lack of a strong indigenous scientific community capable of transforming or generating appropriate technologies? Sub-Saharan Africa has not been able to adapt existing technologies or to generate new ones for its particular situations, partly because resources are scarce and their management make it impossible to fund a research effort on every commodity in every country. The region also lacks the 'critical mass' of indigenous scientists necessary to produce knowledge through basic and applied research.

Hayami and Ruttam classified technology transfer into three inter-related stages, namely: (1) material, (2) design, and (3) capacity transfer. ${ }^{7}$ Whichever 
way we look at it, both material transfer and design transfer are dependent upon the forum of capacity transfer. The movement of an item from point $A$ to point $B$ does not mean it has been transferred. Transferability needs to be defined in terms of its ultimate useability. In Africa, local adaptive research is needed to make use of transferred material together with training that will enable indigenous scientists to use the designs, blueprints, books etc., to conduct adaptive research. The issue then, for Africa, is lack of an adequate human capacity or the absence of a critical mass of sufficiently trained indigenous scientists to bring about this change and maintain it long enough to have an impact.

The reality of these concerns for the Sahel and for Africa as a whole can be expressed in terms of the need for food security. Food security means increased and stable food production at affordable prices. This can be generated through increased inputs. The vital component of this is knowledge, and this knowledge must reside within a critical mass of the indigenous manpower sector. In the words of Ruttan '... only a country that establishes its own research capacity in agriculture can gain access to the advances in knowledge that are available to it from the global scientific community, and embody that knowledge in the technology suited to its own resource and cultural endowments'. ${ }^{15}$ Agricultural research in the West African Sahel suffers from problems that are common in several African countries: old infrastructures, poor maintenance, non-functional equipment, lack of government support, insufficient operating budget, and inadequate personnel.

\section{PERSONNEL IN AGRICULTURAL RESEARCH}

Agricultural research stations in the Sahel are manned by both national and expatriate staff of varying calibre. In 1983 there were more than 600 research professionals in the eight Sahelian countries*, and nearly one-third were expatriates. ${ }^{3}$ Although the remaining 400 African nationals may encourage an impressive view of the manpower situation, it must be recognized that about 200 of these national scientists were in Senegal and the other 200 were distributed in seven different countries with a total population of 20 million people. Very few of these national scientists and researchers have any training beyond the Ingenieur Agronome Diploma. For example, in Niger, out of an estimated 200 researchers in 1985 only 20 percent had the Doctorat de troisieme cycle or above (Fournier, pers. comm.) and of these, more than half were expatriates, thus implying that less than 17 nationals in Niger's

* Burkina Faso, Chad, Cape Verde Islands, The Gambia, Mali, Mauritania, Niger, and Senegal. 
agricultural research had post-graduate degrees. In Mali, out of 347 people involved in agricultural research in 1985 only 15 had the equivalent of an MSc or higher degree.

In the case of Senegal, the national agricultural research department had 267 scientists in 1983. This number was spread over eleven institutions. The Institut Senegalais de Recherche Agronomique (ISRA) alone has ten centres or research stations staffed by 174 professionals of which only 126 are nationals. These professionals are charged with the enormous responsibility of conducting research on animals (cattle, sheep, horse breeding), crops (millet, rice, sorghum, groundnuts, and vegetables) forestry and fisheries and also in the various disciplines. ${ }^{3}$

\section{PLACE OF AGRICULTURE IN NATIONAL DEVELOPMENT}

Both recipient governments and several donor agencies have a biased view of the role of agriculture in national development. They fail to see the value of reliable surpluses in agricultural production as a precondition for the development and expansion of the industrial sector. This attitude is translated into the weak support that is given to agricultural research. The performance of any research unit depends on the financial support it receives. In 1980, Mali, Senegal, and Burkina Faso only spent an average of 0.91 per cent of their agricultural gross national product (GNP) on research. In 1983, the Government of Mali allocated $\$ 1.25$ million to the Institut d'Economie Rurale (only 40 per cent of their budget) to pay salaries of 715 local staff as well as to fund operational activities and meet recurrent costs. Burkina Faso allocated less than \$1 million (actually only \$715000) in 1983 to the Institut Burkinabe de Recherche Agronomique et Zootechnique. The Senegalese government did not set up a university level faculty to teach agriculture to undergraduates until 1979 (19 years after independence) although it was producing graduates for the civil service, industrial, and urban sectors. ${ }^{4}$

The irony of the situation is that while leaders would have us believe that they emphasize agriculture as the 'priority of priorities', and encourage their farmers to produce more food, this lip service is nothing less than expecting a miracle to occur. In the Sahel, this miracle is rainfall. Few Sahelians are convinced that it is not just the erratic rainfall that is responsible for the decline in food production. The reality of the situation is clearly expressed in the words of Edmundo Flores, 'development may take place in a democracy or a dictatorship, under capitalism, socialism, or communism. But it cannot occur without a critical mass of specialists in science and technology. The political decision to develop science and technology requires shifting a 
considerable share of the government's expenditure to education and research over a long period'. 5

But one must hurry to sympathise with the economic situation in these countries. In most cases the external trade balance records astronomical deficit levels on an annual basis and the purchasing power has decreased significantly today from what it was 25 years ago at independence. Most African countries today devote a significant proportion of their total export earnings to debt service; and yet in other cases, the decline in export earnings does not encourage investment in the research sector where a quick-fix solution to the national economic problem is unavailable.

\section{FOREIGN ASSISTANCE-FOOD AID}

The amount of foreign assistance to Africa today is astonishing. One form of this assistance-food aid-while serving a genuine purpose in the face of disasters and catastrophes, does ensure the continuity of the dependency syndrome. Food aid should be viewed as a temporary measure to tide people over, to transport the infirm across a bridge in time. But food aid in the Sahel has come to stay-as an annual exercise. Governments are unable to pronounce budget figures until foreign contributions are firmly obligated. And food aid has deleterious effects: (1) it is a disincentive to produce; (2) it is dehumanizing and subservient; (3) it influences food tastes and preferences; and (4) it upsets national priorities.

Donors have responded to Africa's economic crises by increasing the official development assistance (ODA) from 25 per cent in 1975 to 30.6 per cent in 1983 of total ODA. ${ }^{12}$ In several Sahelian states, the level was substantially higher than anywhere else in the world: Mali- $\$ 27.9$ per person, Burkina Faso - $\$ 35 \cdot 6$, Gambia $-\$ 59 \cdot 5$, Niger- $\$ 33 \cdot 1$ and Senegal$\$ 56.2$. While it is wholesome that the strong assist the weak, often the response of donor agencies to the cry for assistance in almost all sectors has been too frenzied. There has been little in-depth analysis and this has been followed by hastily designed projects. These are implemented with little or no understanding of the itinerant, or constantly recurring problems by a flood of overnight consultants extrapolating incoherent strategics. This process too often upsets an already fractured system and creates a mass of intractable splinters.

Two good examples come from the food production project in the Cassamance in Senegal, and the rainfed farming in the Dosso project in Niger. Both were complete failures. In the latter case the project was hurriedly terminated due to inadequate design and monitoring. ${ }^{17}$ Another example is the USAID/Institut du Sahel's Integrated Pest Management 
Project. From its inception, it was doomed to fail. Without basic knowledge of the major pest species, their biology and distribution, economic importance, threshold levels, or crop loss figures, results were expected in less than five years. These results were to change the Sahelian farmers' production levels of five crops: sorghum, millet, cowpeas, maize, and rice. This project has now been terminated for obvious reasons: poor knowledge of the problem, over-ambitious objectives, poor planning, interstate politicing, and unqualified field 'experts'.

Donors have responded differently to Africa's crises, depending on the sector involved. Dramatic food crises send donors vying for first place in tonnage of food aid. But how have they responded to needed human capital development? The World Bank committed \$105 million to strengthen Senegal's national agricultural research for the period 1981-88. What happens after 1988? The INTSORMIL programme was officially established on 1 July 1979. But as of 30 June 1984 only four Sahelians had participated in INTSORMIL-sponsored training in US universities. ${ }^{10}$ Yet, across the subregion, there is a consistent succession of expatriate technicians, consultants and advisers 'ensuring' that the collective knowledge accumulated is appropriated by the same agencies involved. This explains in part why some of the results of research are often inaccessible to scholars in Africa because they are to be found only in depositories in London, Paris, Bonn, Washington and Rome. The dichotomy leaves one wondering how genuine the advanced nations of the world are in their committment to bring the African peoples to the doorstep of food security.

The arguments presented so far indicate that there is an acute weakness in the resource base of indigenous professional personnel; governments do not accord sufficient support to research; food aid has deleterious effects; and foreign technical assistance is sometimes poorly administered. These factors all combine into another deleterious effect: they cripple the resource base. The number of foreign assistance efforts in any particular country is often beyond the management capabilities of national systems. For example, in 1984, the USAID had approximately 1000 active projects in 35 countries in Africa. ${ }^{4}$ In Mali alone, in 1985 there were eight active and overlapping USAID-financed agricultural research and extension projects. Moreover, few projects have life-spans longer than 2-5 years and several are terminated even while still on the drawing board.

Fortunately, donors are beginning to realize the need for long-term commitments. But while the International Agricultural Research Centres (IARCs) are good indicators of this shift in policy, very few national programmes have received similar commitments. Donors and agencies support components of national projects and often co-sponsor support to various national, regional, and international research and development 
institutions. In Niger, plant protection research and extension is covered by: (1) the National Plant Protection Service of the Ministry of Rural Development; (2) the Plant Protection Division of the Institut National de Recherches Agronomiques du Niger (INRAN) under the Ministry of Agriculture; (3) USAID Niger Cereals project; (4) the German Gesellschaft für Technische Zusammenarbeit (GTZ) project; (5) the Canadian International Development Agency (CIDA) project; and (6) the regional USAID/Institut du Sahel IPM project. These projects are not integrated under one national co-ordinating body. Such an influx and multiplicity of projects stretches the absorptive capacity of the system, weakens the degree of concentration on commodity research, and disrupts focus and priority. This flood of assistance affects the quality of research and results in observational rather than investigative and analytical research. It systematically inhibits the existence in any one place of a strong scientific community. It also limits the perceptive horizon of the individual-the ability to conceptualize, formulate, prioritize, and execute-and creates an unhealthy research environment. The need for nationals to provide the management and administration to service the myriad of donor projects further weakens the capacity of the national system. As a result, some researchers become administrators and project directors, others become disillusioned and complacent and field technicians are left without the necessary technical leadership.

\section{WHAT NEEDS TO BE DONE}

As agricultural scientists concerned with international development, there is little we can do to change government policies and attitudes (such as fiscal and pricing policies and marketing systems) nor can we interfere with food aid and the politics that accompany it. Governments will come and go, and so will various food aid programmes, but the people whose lives are affected will remain. These are the ones that constitute our major asset. We must upgrade the value of our assets, for the more its worth is enhanced, the higher the returns that can be expected from it.

\section{Training}

The facilities available in Sahelian countries for agricultural training are not geared towards producing competent professional scientific leadership. Out of 28 agricultural institutions in four countries (Burkina Faso-5, Mali-5, Niger-4 and Senegal-14) none offers training to MSc or PhD levels. ${ }^{3}$ Consequently, graduate studies are pursued abroad. Since few African governments can meet the cost of overseas graduate studies, support for 
such training relies on foreign assistance. But donor agencies do not often make the most effective possible contribution to the manpower needs of the nation for development, and too often the training offered is geared towards advancing donor mandates or objectives. ${ }^{1}$ As a result, training may not accord with, and may even distort, the priorities that are needed for national development. Our training programmes as they are today emphasize commodity and disciplinary research. But most of our students end up as policy and decision makers. This may not in itself be a bad thing, particularly in cases where present-day policy makers dealing with the agricultural sector have limited or no training in the agricultural sciences. But these programmes should also reflect mechanisms for the training of policy scientists. They should evolve a methodology that enhances a flow, a continuum of relationship between commodity research, cropping systems, farming systems, and the agricultural sector, all within the framework of overall national development.

What this implies is that we should, we must, broaden our resource base through massive human capital investment. Overseas training of our professionals will continue to be needed for the next 25 years; but, training requiring field research at the post-graduate level that is related to agriculture should be done in West Africa.

The International Agricultural Research Centres (IARCs) in Africa should expand their training programmes to encourage national scientists (whether with PhDs or not) to participate in 6-24 months in-service professional enhancement. In some cases this may require special arrangements outside existing centre programme policies, for example, by modifying the prerequisites for interns and visiting scientists. The Centres have a major role to play in the training of young African scientists and this role must be viewed on a long-term basis. The IARCs should be viewed as centres of excellence and inspiration to their national counterparts rather than as competitive elements-a misconception that is not uncommon on both sides.

The ability to borrow and adapt technology to local conditions does not reside solely in the acquisition of an $\mathrm{MSc}$ or $\mathrm{PhD}$. We take it for granted that newly trained and qualified personnel are effective and productive on 'day one'. There is at least a ten-year period between the commencement of graduate training and the productive years of the individual: five years of graduate studies, and five more of gestation and moulding during which an adaptive conceptualization and mind development occurs. Thereafter the ability to generate and deliver the goods takes place.

The drain of trained technical personnel into the administrative sector is only too apparent because their number is limited. This 'brain drain' will continue until both donors/agencies and recipient nations work in consort 
to identify manpower needs as well as articulating what kinds of training are available. Otherwise, faced with the general shortage of professional manpower, governments will continue to accept what they can get in the hope of distributing the end product into their own priority areas.

\section{Leadership}

The great strides in development achieved in the advanced nations have not come about through the simple aggregate effort of the masses. Rather, this aggregate effort was invariably stimulated by the few who had a fuller understanding of development processes, and the place of knowledge in development - the few who drew knowledge from their experiences, both successful and unsuccessful, to design programmes and options appropriate not only for a single sector of the society, but that cut across the developmental needs of their nations.

There is sufficient evidence to justify the claim that most African countries need strong and reliable leadership at all levels of their societies--the Sahelian countries are no exception. Leaders are needed who are committed to the well-being of their peoples; national institute directors who know that knowledge is the key to freedom of the spirit, and freedom from hunger. Leaders who do not obstruct progress are needed; people not complexed by the training of the upcoming generation for fear that their mantle of power will be wrested from them.

\section{Regionalization}

Studies have shown that many, small, lesser-developed countries will not be able to increase their investment in agricultural research to the levels necessary to assemble a critical mass of researchers. Without this investment they will be unable to foster programmes to enable them to adapt development in agricultural sciences and technology to their local needs. Similar conclusions, in summary, by directors of the International Agricultural Research Centres were that 'there are simply too many small African countries with inadequate financial institutional and human resources to mount independent agricultural research programmes'. ${ }^{19}$ They recommended that 'the most efficient approach for Africa may be to develop complementary centres of excellence in the various countries which taken together, would constitute a strong, well-rounded agricultural research system region-wide'.

There are proven examples of successful regional programmes in South America, Asia and southern Africa. Regionalization and/or networking reduces costs, minimizes duplication, boosts efficiency, and favours the much-needed existence of a critical mass of professionals working in the 
same location or project. Plucknett and Smith ${ }^{14}$ enumerated seven basic principles for success in networking: problem definition, commonality of problem, self-interest, commitment of resources, funding, manpower and expertise, and leadership. Given the situation in the Sahel, regionalization and networking should receive wide support. But examples of the West African Rice Development Association (WARDA) and the Institut du Sahel's Integrated Pest Management Project should serve as pointers. In fact, it is known that there is little political support among Sahelian states for regional development activities. ${ }^{2}$

\section{CONCLUSION}

Constraints that hinder the effectiveness of national research institutions are far more extensive than have been discussed in this paper. Some of these lie in the domain of complex political organizations within national systems. The political will of nations, the moral obligations of societies, the merit system and mechanisms of compensation for excellence are areas that need to change from within. Just as technology cannot be imposed, and national development cannot be brought about by external introductions, so must the willpower of a people generate their own internal transformations. These are issues that transcend researchers, who represent but one group of people working to improve the plight of their country.

Donors and agencies genuinely concerned with the African food crises must re-orientate their strategies and priorities. Far more could be achieved if at least half of the present projects were phased out and funds pooled into fewer projects. Such an action would extend the lifespan of remaining projects, encourage continuity both in the expatriate personnel and national programme staff, and hold the promise of more meaningful, substantive accomplishment.

Donor agencies need to reassess their objectives and should demand accountability from recipient countries. A multiplicity of projects, the incoherence of some projects and objectives, and the seeming indifference of some donor agencies in continued assistance to obvious failures have largely contributed to the often-heard phrase-'It is AID money'. The most successful projects so far have been those with marginal but assured longterm funding, small- to medium-scale, with clear objectives, and peopleoriented; not the highly visible, multi-million dollar government-oriented ones.

It is high time that both donor agencies and recipient governments realized that developmental processes can only be generated from within and cannot be introduced, let alone imposed upon a people. Donors should 
insist on counterpart participation both in financial and human resources, no matter how meagre this may be. But at least, an indication of willingness to bring about the necessary changes from within should be a prerequisite.

A people must evolve and, through a natural process of maturity, come to a realization and an appreciation of their needs. The opportunity must be given for them to grow and develop, if such development is to be an integral part of their cultural evolution. Unless leaders (helped through provision of the necessary educational experiences) emerge from within their own ranks to navigate their course, efforts at developmental assistance will continue to falter.

While regional projects may warrant priority over a multiplicity of national projects, a precondition remains for the existence of adequate manpower and expertise. Importation of expatriate staff alone will fall sadly short of bringing about changes in national programmes, in regional projects, and network programmes. The bottom line of the problem is the urgent need to train a massive contingent of national researchers. This does not imply that all national staff should be trained to MSc and PhD levels. On the contrary, the need is just as urgent for para-professional types of training and BSc-level training. Several countries in the Sahel have facilities for training of this sort. Putting them into adequate and efficient use is a moral obligation. Unless national institutions are mandated to cater to national needs, Africa's development prospects will remain disappointing. In summary, the following three mutually inter-active approaches may be envisaged:

(1) Strengthening the research institutions through infusion with a critical mass of well-trained, capable, indigenous scientists, i.e., a long-term investment in human capital development;

(2) strengthening the national capacity to train its own scientists, technical, and para-professional staff at all levels of the research institution; and

(3) strengthening the country's capabilities to make productive use of its scarce scientific resources through redesign of the research institution: objectives, orientation and approach.

\section{ACKNOWLEDGEMENTS}

This paper was prepared while the author was on Sabbatical leave as Adjunct Professor at the University of Florida, Gainesville, FL 32611, USA. The support received from the Center for Tropical Agriculture, International Programs and the Center for African studies is acknowledged. The editorial assistance of $\mathrm{Mr}$ Steve Kearl is appreciated. 


\section{REFERENCES}

1. Bunting, A. H., The TAC study of training in the International Agricultural Research Centres and Institutions. Reading, 1-6 June 1985. 1985. Limited distribution.

2. Development Associates, Evaluation of the Sahel Regional AID Coordination and Planning Project. Washington, DC, USAID, 1984. Limited distribution.

3. DEVRES/Institut du Sahel (INSAH), Assessment of agricultural research resources in the Sahel. 3 vols. Washington, DC, USAID, October 1984.

4. Eicher, C. K., Transforming African agriculture. The Hunger Project papers, No. 4 (Tangri, Beverly (Ed.)), 1986.

5. Flores, E., Science and technology in Mexico: Toward self-determination. Science, 219(1983), 1398-401.

6. Hansen, B., Colonial economic development with unlimited supply of Land: A Ricardian case. Economic Development and Cultural Change. 27(1979), 611-28.

7. Hayami, Y. \& Ruttan, V. W., Agricultural development. An international perspective. Baltimore, The Johns Hopkins University Press, 1985.

8. Hazell, P. B. R. \& Anderson, J. R., Public policy toward technical change in agriculture. Greek Economic Review, 6 (1984), 453-82.

9. Helleiner, G. K., Typology in development theory: The land surplus economy (Nigeria). Food Research Institute Studies, 6 (1966), 181-94.

10. INTSORMIL, Fighting hunger with research. A 5-year technical research report of the sorghum/pearlmillet collaborative Research Support Program(Winn, Judy F. (Ed.)) University of Nebraska, Lincoln, NE. 1985.

11. Matlon, P. J. \& Spencer, D. S., Increasing food production in Sub-Saharan Africa: Environmental problems and inadequate technological solutions. American Journal of Agricultural Economics, 66 (1984), 671-6.

12. OECD (Organization for Economic Cooperation and Development), Development Cooperation, 1984 Review. Paris, 1984.

13. Paulino, L., Global trends in cereal supply and demand and their implications to price environment. Paper prepared for the IFPRI Workshop on Food and Agricultural Policy, Belmont Estate, Elkridge, Maryland, 29 April-2 May 1984.

14. Plucknett, D. L. \& Smith, N. J. H., Networking in international agricultural research. Science, 225 (1984), 989-93.

15. Ruttan, V., The global agricultural support system. Science, 222 (1983), 11.

16. Spencer, D. S. C., Agricultural research in Sub-Saharan Africa: Using the lessons of the past to develop a strategy for the future. Background paper: Committee on African Development Strategies, 17 January 1985 session. Limited distribution.

17. USAID, Inadequate design and monitoring impede results in Sahel food production projects. Regional Inspector General for Audit, 31 January 1984. Washington, DC.

18. World Bank, Accelerated development in Sub-Saharan Africa. An agenda for action. Washington, DC, The World Bank, 1981.

19. World Bank, International agricultural research in Africa: African agricultural research. Center Directors Meeting, Washington, DC, January 1985. Limited distribution. 